\section{Superior pellucid marginal corneal degeneration}

MS Sridhar, S Mahesh, AK Bansal and GN Rao

surgical management required in selected cases.

Eye (2004) 18, 393-399. doi:10.1038/

sj.eye. 6700643

Keywords: pellucid marginal corneal

degeneration; ectatic corneal disorders; corneal topography

degree of astigmatism, slit-lamp examination findings, topographic features, and Orbscan findings were noted where available.

Improvement in visual acuity with spectacles or contact lens correction, surgical procedure if any, and final visual acuity were analysed.

Results In all, six patients were males and two were females. All cases except one were bilateral. The patients ranged in age from 18 to 48 years. All cases had isolated superior PMCD. One patient was a diagnosed case of vernal keratoconjunctivitis. The visual acuity at presentation ranged from hand motions to $20 / 25$. The degree of thinning varied from 30 to $90 \%$. The extent of thinning was commonly

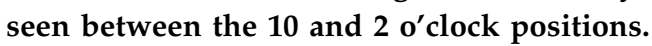
Ectasia was seen below the site of thinning in all the cases of superior PMCD. Topographic features including vertical corridor of reduced power, against-the-rule astigmatism and superior loop cylinder were seen in $\mathbf{1 0}$ eyes. Orbscan was carried out in two eyes of one patient and revealed an area of increased elevation in relation to the best-fit sphere superiorly corresponding to the area of ectasia in both the eyes. The visual acuity improved with rigid gas-permeable contact lens in six eyes and the final visual acuity ranged from 20/ 400 to 20/30. Two eyes were subjected to surgical intervention (peripheral annular graft $=1$ and lamellar graft $=1$ ).

Conclusions PMCD can occur superiorly. It should be considered in the differential diagnosis of superior ectatic disorders. The topographic findings, of reduced power in the vertical meridian and superior loop cylinder, are typical of superior pellucid marginal degeneration. Visual rehabilitation is usually possible with contact lenses, with

\section{Introduction}

Pellucid marginal corneal degeneration (PMCD) is a bilateral noninflammatory ectatic peripheral corneal disorder usually involving the inferior portion of the cornea. ${ }^{1}$ It occurs in the fourth to fifth decades of life and presents as decreased visual acuity due to high irregular against-therule astigmatism. ${ }^{2}$ The cornea typically shows a crescentric area of thinning, from the 4 to 8 o'clock position, 1-2 $\mathrm{mm}$ from the limbus. The area separating the thinning from the limbus is normal, while the cornea superior to it is ectatic. ${ }^{3}$ The high against-the-rule astigmatism and inferior steepening results in the classical topographic features of reduced corneal power in the vertical meridian and increased power in the peripheral cornea inferior to the lesion site. ${ }^{4}$ This area of increased power (loop cylinder) usually extends upwards along the cornea in the horizontal oblique hemimeridians. We report eight patients (15 eyes) of superior pellucid marginal degeneration with topographic features.

\section{Methods}

We retrospectively reviewed the records of all cases of superior PMCD seen in the cornea service at LV Prasad Eye Institute, a tertiary eyecare centre in Hyderabad, India. A detailed clinical history including the age of onset of symptoms, family history, any associated systemic diseases or atopy was obtained from all the patients. Slit-lamp biomicroscopic examination in all the cases detected the extent
Cornea Center LV Prasad Eye Institute Hyderabad, India

Correspondence: MS Sridhar Cornea Services LV Prasad Eye Institute LV Prasad Marg Hyderabad 500034, India Tel: 914023548267 Fax: 914023548271 E-mail: mss@

Ivpeye.stph.net

Received: 16 December 2002

Accepted in revised form: 1 May 2003 
and degree of thinning as well as the presence of other ectatic conditions. Topographic evaluation was carried out with TMS-1 videokeratoscope (version 1.61). In addition, case no. 2 was evaluated using the orbscan topography system (version 3.0). The case details of patient no. 2 are described below.

\section{Case report}

A 45-year-old woman presented to us on 6 July 2001 for the management of high astigmatic error in both the eyes. Her medical history was positive for hyperthyroidism. No history of atopy could be elicited. The best-corrected visual acuity in the right eye was 20/30 with + 7Dsph/ -16 Dcyl $\times 75$ and in the left eye was $20 / 40$ with +6 Dsph/ -13 Dcyl $\times 110$. Biomicroscopic examination showed clear corneas in both the eyes with no evidence of any inflammation or vascularization. There was a crescent shaped thinning about $2 \mathrm{~mm}$ from the limbus extending from 10 to $12 \mathrm{o}^{\prime}$ clock positions in both the eyes (Figure 1). The area inferior to thinning was ectatic (Figure 2). The right eye had about $30 \%$ thinning and the left eye had $50 \%$ thinning. The inferior cornea was normal in both the eyes. The rest of the anterior segment was unremarkable except for a few anterior cortical lenticular opacities in the right eye. Topographic evaluation revealed against-the-rule astigmatism with the corridor of lowest power at about $70^{\circ}$ in the right eye and $115^{\circ}$ in the left eye (Figures 3 and 4 ).

Orbscan findings showed an area of increased elevation in relation to the best-fit sphere superiorly corresponding to the area of ectasia in both the eyes (Figures 5 and 6). Further in the horizontal meridian, the corneal surface showed progressive depression from the centre to the periphery, suggesting steepening. The patient underwent a rigid gas-permeable contact lens

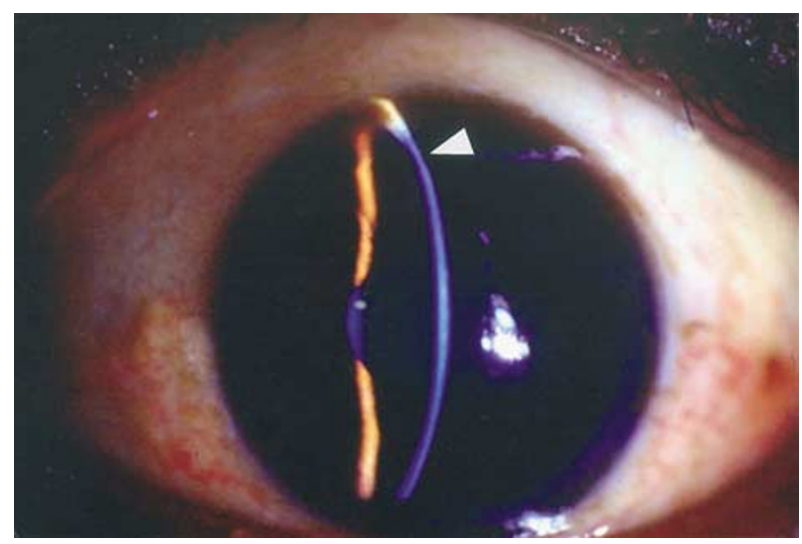

Figure 1 Slit-lamp view of the right eye of case no. 2 showing thinning superiorly away from the limbus.

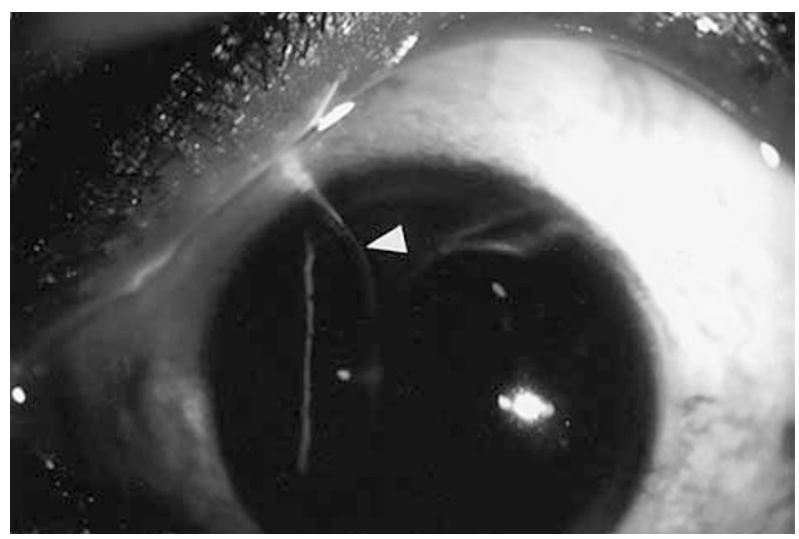

Figure 2 Slit-lamp view of the same patient (left eye) showing the ectasia inferior to site of thinning.

trial and the best-corrected visual acuity was 20/25 in the right eye and 20/30 in the left eye.

\section{Results}

The salient clinical features of the 15 eyes of eight patients are summarized in Table 1. Of these patients, six were males and two were females. All the patients in this series were bilateral except one. Patient no. 3 had topographic evidence of early PMCD in the right eye. The age of the patients ranged from 18 to 48 years. Patient no. 8 was a diagnosed case of vernal keratoconjunctivitis and she was not on topical steroids. All the cases had isolated superior PMCD. One case had associated secondary keratoglobus. The visual acuity at presentation ranged from hand motions to $20 / 25$. The degree of thinning varied from 30 to $90 \%$. In eight eyes, the extent of thinning was from 10 o'clock to $2 \mathrm{o}^{\prime}$ clock positions. The topographic features in 10 out of 16 eyes were consistent with the findings of superior PMCD (Table 2). The corneal power was markedly lower in the vertical meridian with a superior loop cylinder peripheral to the area of thinning. The right eye of patient nos. 1, 4, 6 and the left eye of patient no. 8 had a distorted pattern due to scarring. The scarring is probably because of resolved hydrops in 10 cases. The left eye of patient no. 3 had a keratoglobus-like pattern and the left eye of patient no. 6 had an asymmetric bow-tie pattern. Six eyes were subjected to rigid gas-permeable contact lens fitting for visual rehabilitation. In two more eyes, RGP contact lens trial was advised. The final visual acuity in those treated with contact lenses ranged from 20/400 to 20/30. Two eyes were subjected to surgery. Patient no. 1 underwent lamellar keratoplasty in the right eye. He had a final visual acuity of 20/50 at 14 months follow-up with a residual astigmatism of 6 D. Patient no. 5 had a peripheral annular graft in the right eye. He had a visual 


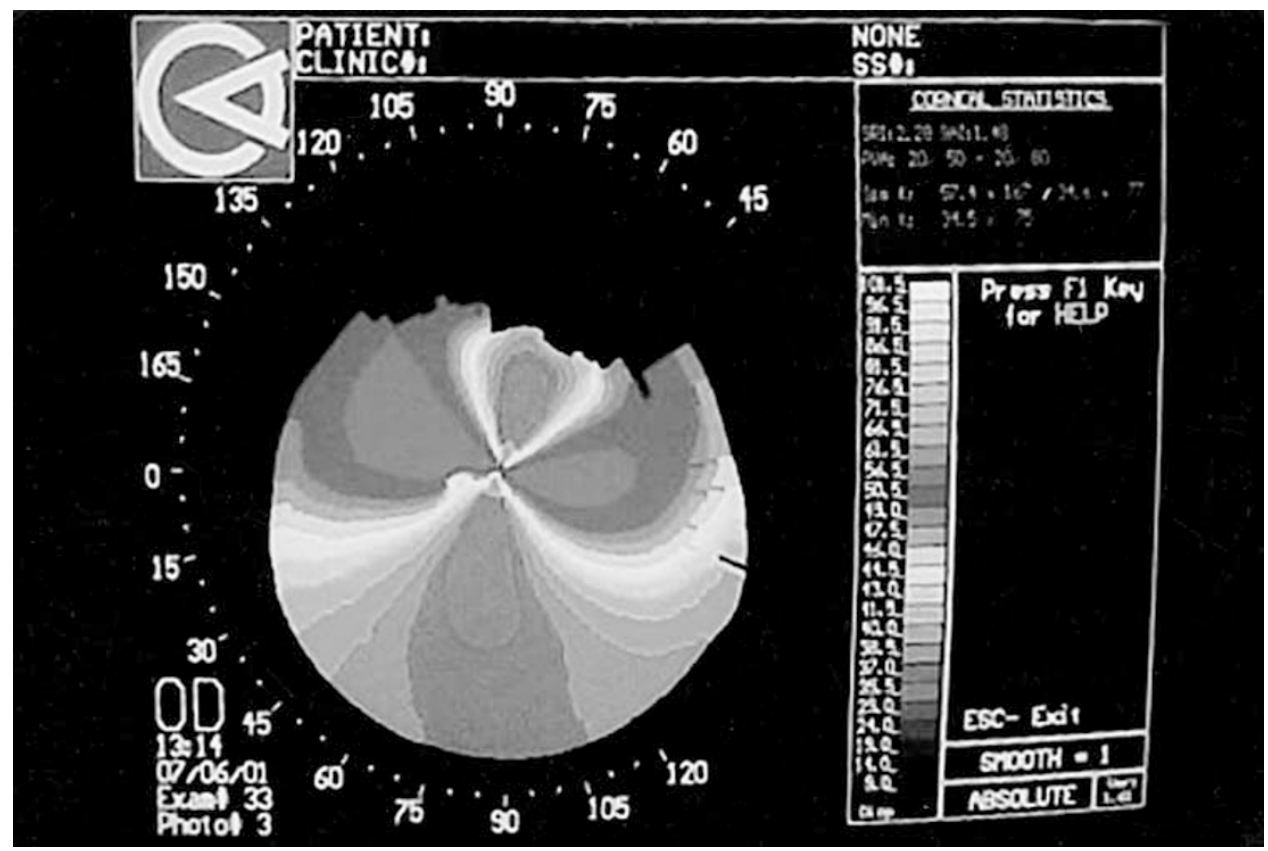

Figure 3 Topography of the right eye of the same patient showing the axis of reduced power at $70^{\circ}$ with a bow-tie pattern. Note that the superior loop cylinder is not seen in this picture.

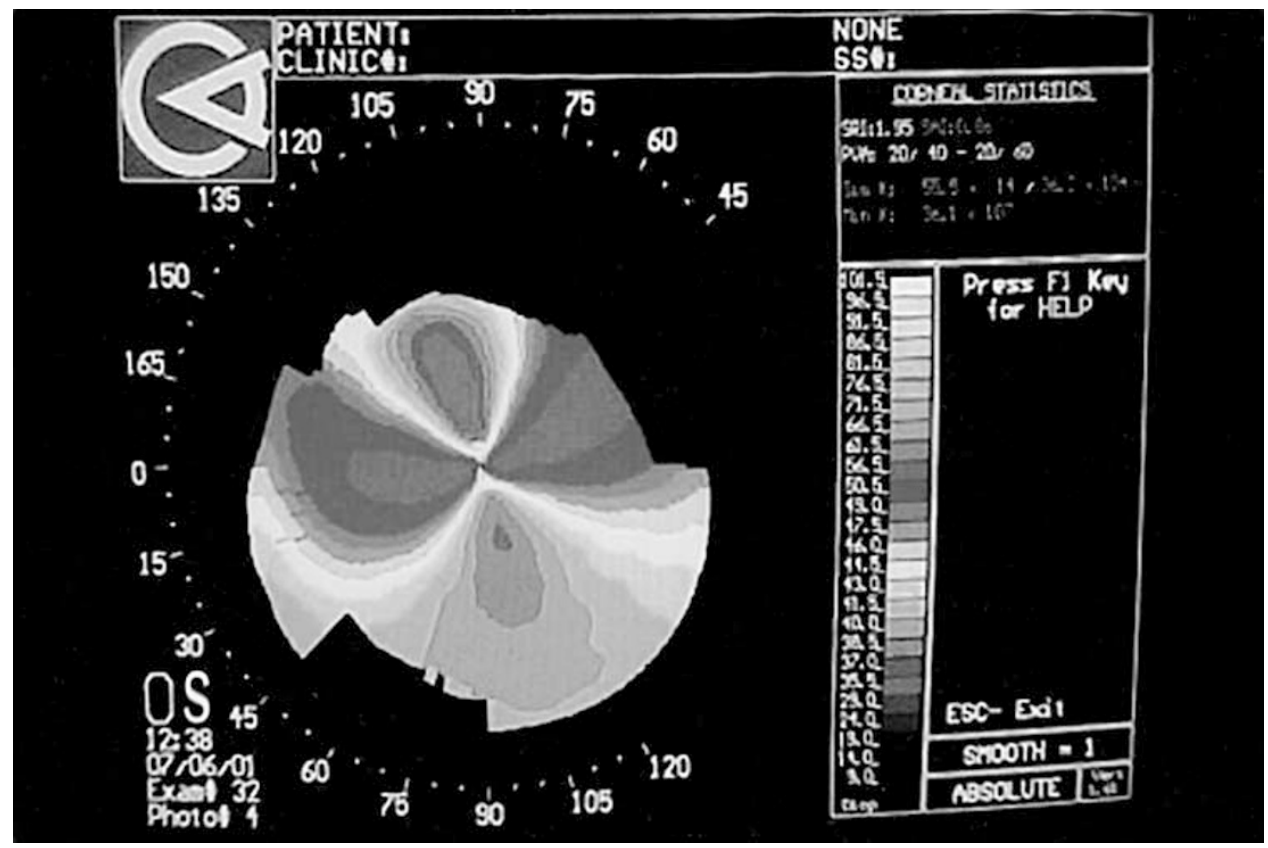

Figure 4 Topography of the left eye of the same patient showing changes similar to Figure 3 with the shifting of the meridian of least power to $115^{\circ}$.

acuity of 20/100 with 7D of astigmatism at his last visit, 2 months following surgery. Patient no. 7 had almost total cataract in both the eyes, the cause of which was not clear. She underwent cataract surgery. RGP contact lens trial was advised after surgery.

\section{Discussion}

PMCD is a rare clinical entity. ${ }^{1}$ Although PMCD is a bilateral disorder, atypical unilateral cases have been reported. ${ }^{5,6}$ The reported age of onset in the literature is 


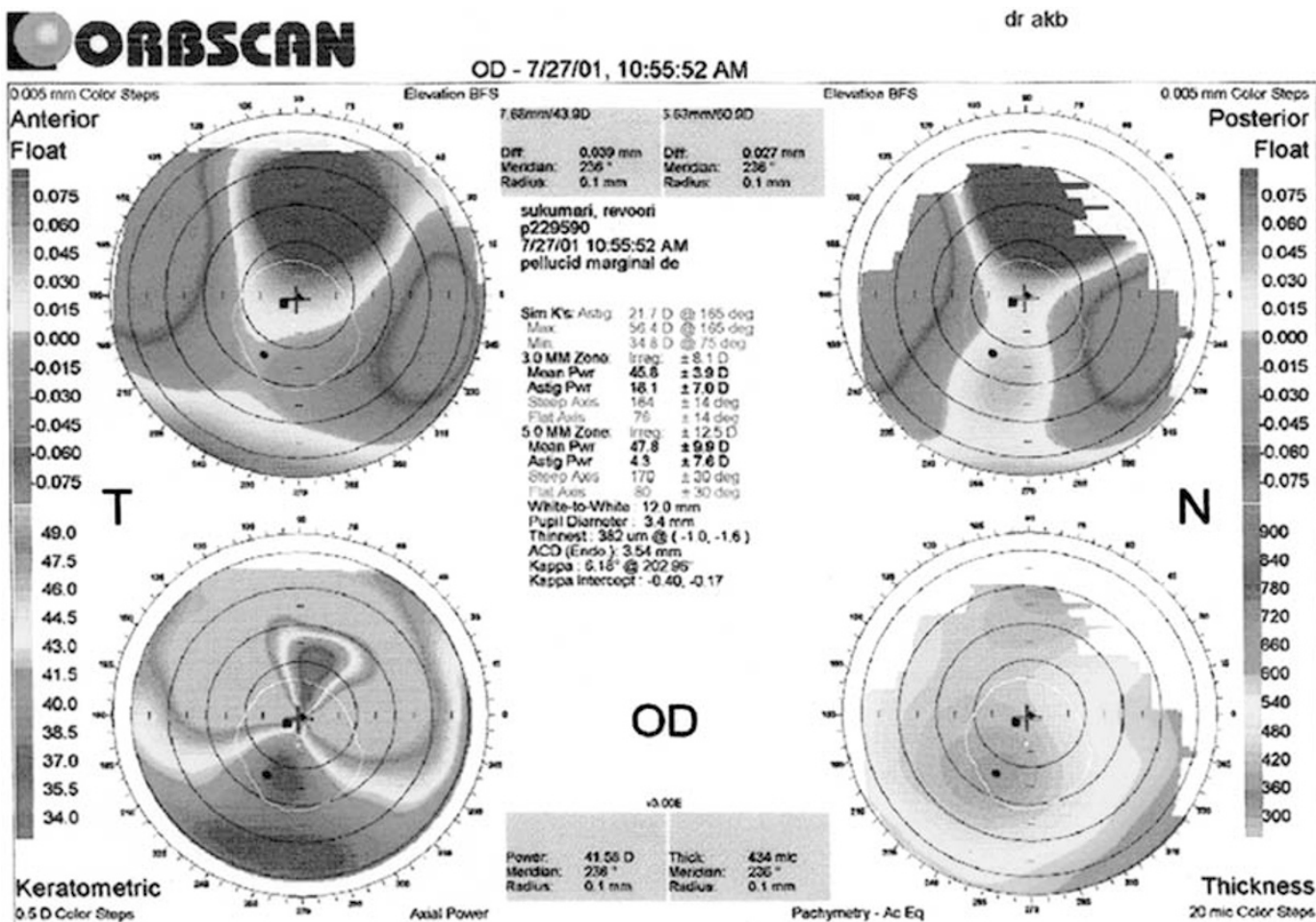

Figure 5 Orbscan elevation BFS map of the right eye of the same patient showing the area of increased elevation seen in both the anterior and posterior float. Moreover, note the keratometric map showing the superior loop cylinder with extension onto horizontal hemimeridians.

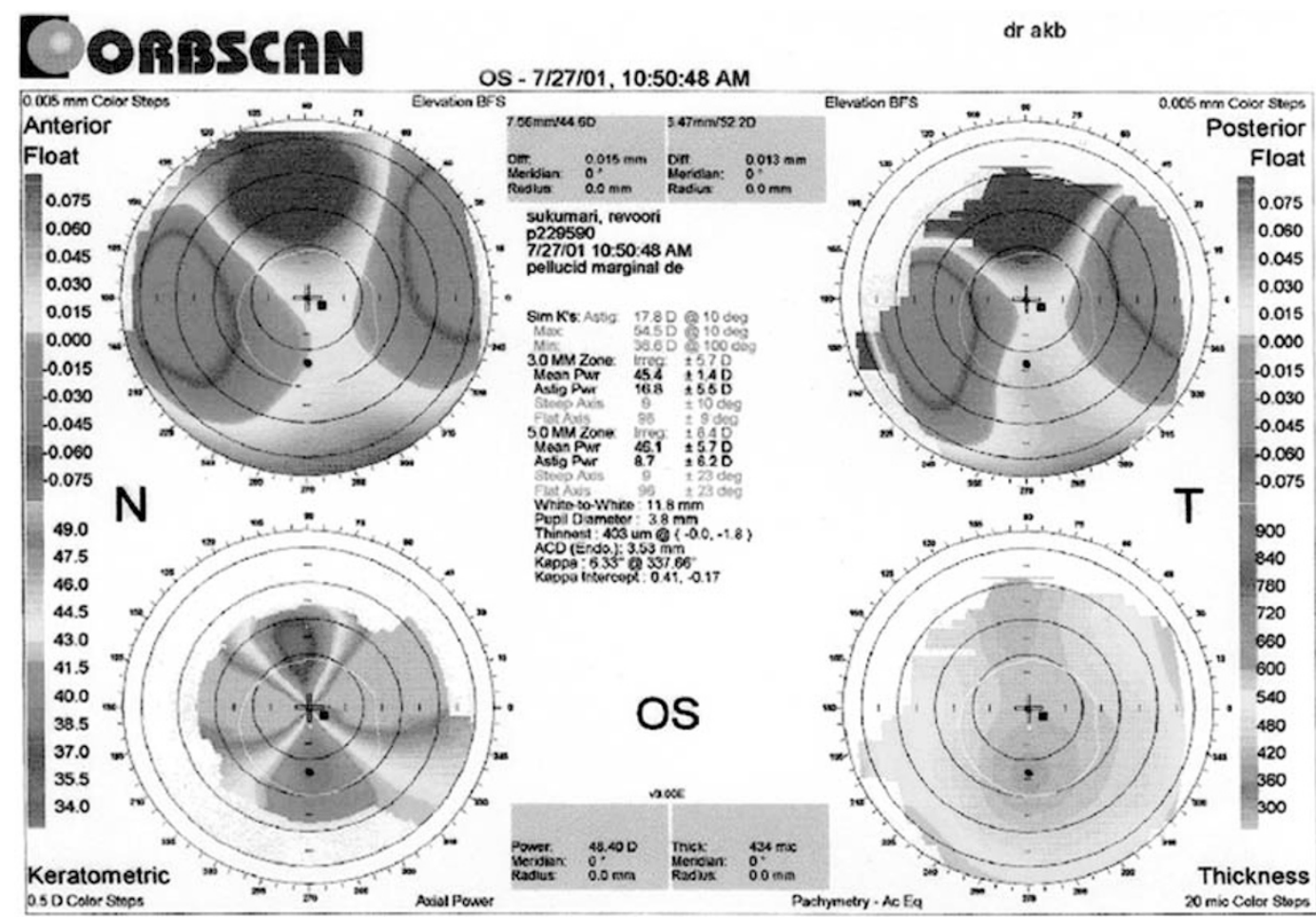

Figure 6 Orbscan elevation map of the left eye of the same patient showing a similar area of increased power superiorly. Also seen is an increasing depression in the horizontal meridian towards the periphery from the centre. 
Table 1 Clinical features

\begin{tabular}{|c|c|c|c|c|c|c|c|}
\hline Sl no. & $\begin{array}{c}\text { Age of onset/sex } \\
\text { (years) }\end{array}$ & Laterality & $\begin{array}{l}\text { Visual acuity at } \\
\text { presentation }\end{array}$ & $\begin{array}{l}\text { Thinning } \\
(\%)\end{array}$ & $\begin{array}{c}\text { Extent } \\
\text { (clock hours) }\end{array}$ & $\begin{array}{c}\text { Associated } \\
\text { Keratoglobus }\end{array}$ & $\begin{array}{c}\text { Final visual acuity } \\
\text { after treatment }\end{array}$ \\
\hline & & OD & $\mathrm{HM}$ & NA & NA & + & $\mathrm{HM}$ \\
\hline \multirow[t]{2}{*}{1} & $48 / \mathrm{M}$ & OS & $20 / 120$ & NA & $12-4$ & - & $20 / 80$ \\
\hline & & OD & $20 / 600$ & 30 & $10-2$ & - & $20 / 25$ \\
\hline \multirow[t]{2}{*}{2} & $45 / F$ & OS & $20 / 600$ & 50 & $10-2$ & - & $20 / 30$ \\
\hline & & OD & $20 / 20$ & NIL & NIL & - & $20 / 20$ \\
\hline \multirow[t]{2}{*}{3} & $46 / \mathrm{M}$ & OS & $20 / 1200$ & 50 & $10-2$ & - & $20 / 125$ \\
\hline & & OD & $20 / 1200$ & 90 & $10-2$ & - & $20 / 400$ \\
\hline \multirow[t]{2}{*}{4} & $41 / \mathrm{M}$ & OS & $20 / 200$ & 70 & $10-2$ & - & $20 / 40$ \\
\hline & & OD & $20 / 1200$ & 70 & $9-1$ & - & $20 / 100$ \\
\hline \multirow[t]{2}{*}{5} & $35 / \mathrm{M}$ & OS & $20 / 30$ & 40 & $12-4$ & - & $20 / 80$ \\
\hline & & OD & $20 / 400$ & 70 & $10-2$ & - & $20 / 30$ \\
\hline \multirow[t]{4}{*}{6} & $20 / \mathrm{M}$ & OS & $20 / 25$ & NIL & NIL & - & $20 / 20$ \\
\hline & & OD & $\mathrm{CF}$ & NA & $10-2$ & - & $20 / 25$ \\
\hline & & & & & & & $20 / 100$ \\
\hline & & & & & & & (after cataract surgery) \\
\hline \multirow[t]{2}{*}{7} & $18 / \mathrm{F}$ & OS & $\mathrm{HM}$ & NA & $10-2$ & - & $20 / 125$ \\
\hline & & OD & $20 / 400$ & 70 & $10-1$ & - & $20 / 25$ \\
\hline 8 & $22 / \mathrm{F}$ & OS & $20 / 50$ & NA & $11-2$ & - & \\
\hline
\end{tabular}

M, male; B/L, bilateral; F, female; NIL, no thinning clinically detected; NR, not recordable; NA, data not available; HM, hand motions; U/L, unilateral; $\mathrm{D}$, dioptres

the fourth to fifth decade. ${ }^{1}$ Cameron and Mahmood ${ }^{3}$ have reported the association of atopy and vernal keratoconjunctivitis in their series of patients with superior corneal thinning with PMCD. PMCD differs from other ectatic disorders in its characteristic inferior location and lack of inflammatory signs. ${ }^{7}$ The site of ectasia is the normal cornea, above the zone of maximum thinning. This differs from keratoconus where protrusion occurs at the site of maximum thinning. ${ }^{8}$ Although usually described as involving the inferior four clock hours, superior corneal involvement associated with inferior PMCD has been reported in the literature., ${ }^{3,-9}$ Bower $e a^{7}$ reported a case with superior PMCD with less prominent inferior corneal thinning along with high against-the-rule astigmatism. ${ }^{8}$ Tagalia and Sugar ${ }^{9}$ reported two cases with characteristic features of PMCD with involvement of superior cornea only. Rao $e t a l^{8}$ reported corneal topographic changes in five patients with atypical pellucid marginal degeneration. Isolated superior PMCD was seen in three eyes. The site of thinning can occur in any quadrant. Rao $e^{2} a^{8}$ had a case with nasal PMCD in their series.

In our series, the age of the patients ranged from 18 to 48 years. Most of the patients were males. Only one patient had associated vernal keratoconjunctivitis. In this series, patient no. 3 had superior PMCD in the left eye with only videokeratographic signs of superior ectasia in the other eye. Topographic features of PMCD with no clinical signs have been reported with typical, inferior PMCD. $^{2}$
The classical topographic picture described includes reduced corneal power in the vertical axis and increased power in the peripheral cornea inferior to the site of lesion. This area of increased power (loop cylinder) usually extends upward along the corneal horizontal oblique hemimeridians. ${ }^{7}$ A similar picture has also been described in other ectatic disorders such as Terriens marginal corneal degeneration. ${ }^{10}$ However, the steepening of inferior periphery with extension to the horizontal oblique meridians is believed to be characteristic of PMCD. ${ }^{2}$ In the case of superior PMCD, thinning occurs in a crescent-shaped area superiorly and the area inferior to the site of thinning is ectatic.

Consequently, the topographic picture also varies with a shift of loop cylinder to the superior quadrant. Hence instead of the classical inferior loop, there is a superior loop cylinder peripheral to the area of thinning. ${ }^{2}$

In this case series, there was superior thinning of the cornea with ectasia. Corneal topography showed typical features of superior PMCD in 10 of the 16 eyes. The flattening in the vertical meridian is due to the stromal thinning and tissue loss in a semilunar pattern. ${ }^{2}$ The steepening and protrusion occur at the border of the unaffected tissue, causing the characteristic high cylindrical loop. The high against-the-rule astigmatism is due to a paradoxical steepening at $90^{\circ}$ due to a coupling phenomenon. In all the eyes, the axis of least corridor of power shifted according to the site and extent of thinning. This axis of least power, as well as the location of loop cylinder depended on the site, extent and spread 
Table 2 Topographic features

\begin{tabular}{|c|c|c|c|c|}
\hline No. & Topographic features & SIM K & Refraction & Correction \\
\hline \multirow[t]{2}{*}{1} & $\begin{array}{l}\text { OD_-distorted pattern due to scarring with } \\
\text { irregular astigmatism }\end{array}$ & $\begin{array}{l}52.7 \times 152 / \\
41.1 \times 150\end{array}$ & NA & Lamellar graft \\
\hline & $\begin{array}{l}\text { OS - axis of lowest power at } 60^{\circ} \text { with against-the- } \\
\text { rule astigmatism, no extension into the horizontal } \\
\text { oblique meridians }\end{array}$ & $46.8 \times 150 / 41.1 \times 60$ & NA & - \\
\hline \multirow[t]{2}{*}{2} & $\begin{array}{l}\text { OD-vertical axis of lowest power at } 70^{\circ} \text { with } \\
\text { against-the-rule astigmatism and upturning along } \\
\text { the oblique meridians }\end{array}$ & $55.5 \times 160 / 36.2 \times 70$ & $+7 \mathrm{DS} /-16 \mathrm{DC} \times 75^{\circ}$ & Contact lenses OU \\
\hline & OS - similar to OD with vertical axis at $115^{\circ}$ & $57.4 \times 25 / 34.6 \times 115$ & $+6 \mathrm{DS} /-13 \mathrm{DC} \times 110^{\circ}$ & \\
\hline \multirow[t]{2}{*}{3} & $\begin{array}{l}\text { OD-superior inferior asymmetry with superior } \\
\text { peripheral steepening and skewing at } 120^{\circ}\end{array}$ & $44.1 \times 169 / 43.3 \times 79$ & $+1 \mathrm{DS} /-2 \mathrm{DC} \times 90^{\circ}$ & Spectacles \\
\hline & $\begin{array}{l}\text { OS-increased zone of central power like in } \\
\text { keratoglobus reflecting extension of steepening to } \\
\text { the centre }\end{array}$ & $59.7 \times 169 / 54.7 \times 79$ & $+0.5 \mathrm{DS} /-5 \mathrm{DC} \times 85^{\circ}$ & Contact lens \\
\hline \multirow[t]{2}{*}{4} & $\begin{array}{l}\text { OD—distorted topographic pattern due to } \\
\text { scarring }\end{array}$ & $57.0 \times 165 / 35.1 \times 75$ & $-2 \mathrm{DS} /-15 \mathrm{DC} \times 80^{\circ}$ & Contact lens \\
\hline & $\begin{array}{l}\text { OS-decreased power along the } 75^{\circ} \text { axis with } \\
\text { increasing power in the periphery turning to } \\
\text { oblique meridians as in classical PMCD }\end{array}$ & $55.1 \times 0 / 43.0 \times 90$ & $-1.5 \mathrm{DS} /-10 \mathrm{DC} \times 90^{\circ}$ & Contact lens \\
\hline \multirow[t]{2}{*}{5} & $\begin{array}{l}\text { OD - vertical corridor of lowest power at } 120^{\circ} \\
\text { Increased power towards the superior periphery } \\
\text { No extension to the oblique meridians }\end{array}$ & $60.5 \times 24 / 38.2 \times 114$ & $+1.5 \mathrm{DS} /-7 \mathrm{DC} \times 120^{\circ}$ & $\begin{array}{l}\text { Peripheral annular } \\
\text { graft }\end{array}$ \\
\hline & $\begin{array}{l}\text { OS-axis of lowest power at } 60^{\circ} . \text { Not extending to } \\
\text { the hemimeridians }\end{array}$ & $51.8 \times 138 / 43.9 \times 48$ & $+2 \mathrm{DS} /-6 \mathrm{DC} \times 60^{\circ}$ & Contact lens \\
\hline \multirow[t]{2}{*}{6} & OD_-distorted pattern & NA & $-15 \mathrm{DC} \times 80^{\circ}$ & $\begin{array}{l}\text { Not comfortable } \\
\text { with CL. Advised } \\
\text { lamellar } \\
\text { keratoplasty }\end{array}$ \\
\hline & OS-asymmetric bow-tie pattern & $49.0 \times 10 / 42.4 \times 100$ & $+1 /-7.5 \mathrm{DC} \times 100^{\circ}$ & Spectacles \\
\hline \multirow[t]{2}{*}{7} & $\begin{array}{l}\text { OU_-against-the-rule astigmatism and upturning } \\
\text { along the oblique axis }\end{array}$ & $52.3 \times 42 / 48 \times 132$ & $+6.5 \mathrm{DS} /-15 \mathrm{DC} \times 90^{\circ}$ & $\begin{array}{l}\text { OU-spectacles } \\
\text { advised CL trial }\end{array}$ \\
\hline & & $\begin{array}{l}53.3 \times 145 / \\
42.9 \times 155\end{array}$ & $+4 \mathrm{DS} /-10 \mathrm{DC} \times 100^{\circ}$ & \\
\hline \multirow[t]{2}{*}{8} & $\begin{array}{l}\text { OD-against-the-rule astigmatism upturning } \\
\text { along the oblique meridians }\end{array}$ & $51.1 \times 34 / 35 \times 124$ & $+4 \mathrm{DS} /-15 \mathrm{DC} \times 120^{\circ}$ & - \\
\hline & OS-irregular pattern & $44.3 \times 166 / 41.7 \times 76$ & $-2 \mathrm{DC} \times 100^{\circ}$ & Spectacles \\
\hline
\end{tabular}

NA, data not available; OD, right eye; OS, left eye; OU, both eyes.

of circumferential thinning. Orbscan slit-scan topography evaluation delineated the extent of ectasia in corneal surfaces and correlated with the TMS findings. There have been reports suggesting the possibility of PMCD preceding keratoglobus. ${ }^{2}$ One of our cases had associated secondary keratoglobus. This suggests that PMCD may form a part of the spectrum of ectatic disorders where a combination of these conditions might be seen.

We report this series to highlight that PMCD can occur superiorly. Apart from this series, the literature is sparse on superior PMCD. ${ }^{8,9}$ We reviewed all cases of PMCD seen during a 1-year period between 1 July 2001 and 30 June 2002. We studied cases during this 1 year period because we are now aware of superior PMCD and we are actively looking for it. In all, 19 cases of PMCD presented at our clinic during this period and four $(21.05 \%)$ of these were isolated superior PMCD. Three out of 19 patients (15.8\%) had keratoconus associated with inferior PMCD. We speculate that we are diagnosing more patients of superior PMCD because difficult cornea cases from all parts of the country are referred to our tertiary-care centre. The other probable reason is that we are taking more care in evaluating patients with peripheral corneal ectatic disorders.

To conclude, PMCD can occur superiorly. PMCD should be considered in the differential diagnosis of superior corneal ectatic disorders. The topographic picture is characteristic with a vertical meridian of least power and the superior loop cylinder. Visual rehabilitation is usually possible with contact lens, and surgery may be required in selected cases. 


\section{References}

1 Krachmer JH. Pellucid marginal degeneration. Arch Ophthalmol 1978; 96: 1217.

2 Karabatsas CH, Cook SD. Topograhic analysis in pellucid marginal degeneration and keratoglobus. Eye 1996; 10: 451-455.

3 Cameron JA, Mahmood MA. Superior corneal thinning with pellucid marginal degeneration. Am J Ophthalmol 1990; 109 . 486-487.

4 Maguire LJ, Klyce SD, McDonald MB, Kaufman HE. Corneal topograhpy of pellucid marginal degeneration. Ophthalmology 1987; 94: 519-524.

5 Wagenhorst BB. Unilateral Pellucid marginal degeneration in an elderly patient. Br J Ophthalmol 1996; 80: 927-928.
6 Basak SK, Hazar TK, Bhattacharya D, Sinha TK. Unilateral pellucid marginal degeneration. Indian J Ophthalmol 2000; 48(3): 233-234.

7 Bower KS, Dhaliwal DK, Barnhorst Jr DA, Warnicke J. Pellucid marginal degeneration with superior corneal thinning. Cornea 1997; 16: 483-485.

8 Rao SK, Fogla R, Padmanabhan P et al. Corneal topography in atypical pellucid marginal degeneration. Cornea 1999; 18(3): 265-272.

9 Tagalia DP, Sugar J. Superior pellucid marginal corneal degeneration with Hydrops. Arch Ophthalmol 1997; 115: 274-275.

10 Wilson SE, Lin DTC, Klyce SD et al. Terrien's marginal degeneration: corneal topography. Refract Corn Surg 1990; 6: 15-20. 